\title{
UJI USES AND GRATIFICATIONS DALAM INTENSITAS MENONTON PROGRAM TALK SHOW MELALUI TELEVISI
}

\author{
RIZCA HAQQU
}

Program Studi Ilmu Komunikasi, Universitas Telkom

Jl. Telekomunikasi Terusan Buah Batu, Bandung, Jawa Barat 40257

Email: rizcahaqqu@gmail.com | Telepon: 081325225900

ABSTRAK Sebuah survei tentang konsumsi media di beberapa kota seluruh Indonesia menunjukkan bahwa penggunaan televisi masih mendominasi. Hasil survei yang dilakukan oleh Komisi Penyiaran Indonesia memaparkan program televisi yang dianggap memiliki kualitas dengan nilai standar tinggi sebesar 3.04 adalah program talk show. Tujuan dari penelitian ini adalah untuk menguji sebuah penggunaan media dan hubungan yang mendasarinya berdasarkan sudut pandang teori uses and gratification. Penelitian ini menggunakan teori uses and gratification. Teori uses and gratification menganggap media massa tidak memiliki kekuatan untuk memengaruhi audiens, melainkan khalayak menggunakan media massa tentunya berdasarkan atas keperluan dan kebutuhan yang berbedabeda. Pendekatan kuantitatif eksplanatif digunakan dalam penelitian ini dengan tujuan untuk menjelaskan suatu fenomena sosial yang dapat diukur. Hasil temuan uji korelasi dalam penelitian ini menjelaskan bahwa kepuasan hiburan yang didapatkan oleh responden bukan berasal dari intensitas responden ketika menonton program acara talk show melalui media televisi, melainkan tingginya tingkat kepuasan hiburan yang didapatkan oleh responden berasal dari besarnya motif informasi yang diinginkan.

Kata Kunci: Talk show, televisi, uses and gratification.

ABSTRACT

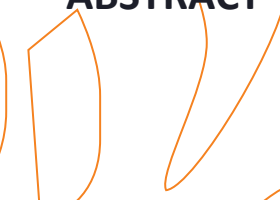

ᄀ

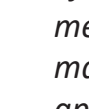
mass media is certainly based on different needs. An explanatory quantitative approach is used in this study to explain a social phenomenon that can be measured. Correlation test results in this study explained that the entertainment satisfaction obtained by respondents did not come from the intensity of the respondents when watching talk show s through television media, but the high level of entertainment satisfaction obtained by respondents came from the magnitude of the desired information motive.

A survey of media consumption in several cities throughout Indonesia shows that television use still dominates. The results of a survey conducted by the Indonesian Broadcasting Commission explained that television programs considered to have quality with a high standard value of 3.04 were talk show programs. The purpose of this study is to examine the use of media and its underlying relationships based on the standpoint of the uses and gratification theory. This research uses theories of uses and gratification. The theory of uses and gratification considers that mass media do not have the power to influence the audience, but the audience using

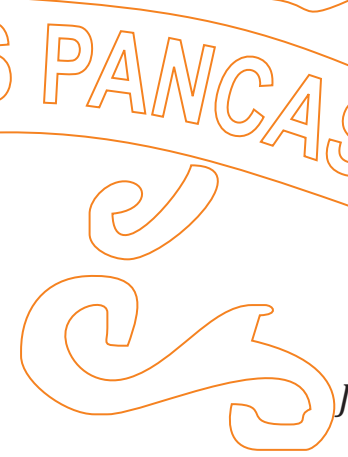
.

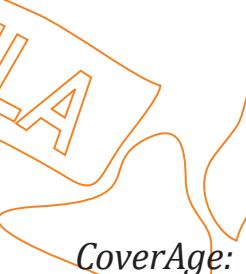
Journal of Strategic Communication Vol. 10, No. 2, Hal. 11-18. Maret 2020

Fakultas Ilmu Komunikasi, Universitas Pancasila 


\section{PENDAHULUAN}

Di era kemajuan teknologi yang sangat pesat, masyarakat dimudahkan mengakses informasi dari berbagai belahan dunia. Alvin Toffler menyatakan bahwa masyarakat saat ini merupakan masyarakat informasi. Ketergantungan akan sebuah media seakan membuat masyarakat modern tidak bisa hidup tanpa adanya akses informasi (Dewi, 2001).

Masyarakat dapat dikatakan sebagai komunitas yang memiliki tatanan sosial dan budaya yang berbeda; dan dalam penggunaan media masyarakat dikategorikan sebagai audiens (Haqqu, 2019). Audiens merupakan penerima pesan-pesan yang berjumlah banyak dan heterogen. Salah satu konsep mendefinisikan audiens sebagai kumpulan penonton, pembaca, pendengar, dan pemirsa (McQuail, 1996).

Sebuah survei tentang konsumsi media di beberapa kota seluruh Indonesia menunjukkan bahwa penggunaan media televisi masih mendominasi. Sebuah riset menjelaskan bahwa prosentase penggunaan televisi di masyarakat Indonesia adalah sebagai berikut: Televisi (95\%), lalu Internet (33\%), Radio (20\%), Surat kabar (12\%), Tabloid (6\%) dan Majalah (5\%) (Lubis, 2017). Televisi merupakan media konvensional berbasis audiovisual yang sudah akrab dengan kehidupan sehari-hari masyarakat Indonesia. Karena sifatnya yang audio visual, televisi dapat menghadirkan acara musik, film, sinetron, variety show, reality show serta acara lainnya dengan melibatkan para selebritis idola khalayak (Abdullah \& Puspitasari, 2018). Berbagai jenis program ditayangkan setiap harinya. Drama, iklan, berita, dan program lainnya menghadirkan sebuah dunia tentang gambaran yang berkaitan dengan kehidupan sehari-hari (Littlejohn \& Foss, 2010).

Hasil survei yang dilakukan oleh KPI (Komisi Penyiaran Indonesia) pada periode 2017 memaparkan salah satu program televisi yang dianggap memiliki kualitas adalah program talk show dengan nilai 3.04 (Komara, 2017). Bila dipandang dari perspektif social budaya, semakin banyaknya pilihan audiens untuk menonton acara-acara yang mereka sukai menunjukkan bahwa industri budaya menghasilkan konten yang terstandardisasi (Permana et al., 2019).

Program acara talk show merupakan salah satu program televisi favorit masyarakat yang dikemas dalam berbagai macam konsep yang berbeda. Program talk show masuk ke dalam kategori program informasi di mana program siaran dibuat dengan tujuan memberikan wawasan pengetahuan kepada penontonnya. Wibowo (2007) menjelaskan dalam acara talk show menghadirkan tokoh-tokoh sebagai narasumber yang saling berargumen serta mengemukakan pendapat dan presenter atau host bertindak sebagai moderator yang mengatur berjalannya diskusi dan memberikan pertanyaan.

Di beberapa stasiun televisi program talk show biasa dikemas dengan santai dan informatif dan ada pula yang dikemas dengan pembahasan yang lebih tajam, aktual, dan informatif. Adanya keinginan khalayak menonton program talk show tidak terlepas dari motif-motif yang mendasari sebuah keinginan. Dari keinginan yang terpenuhi maka akan tercapai sebuah kepuasan. Littlejohn, Foss, \& Oetzel (2017) menjelaskan bahwa khalayak media termotivasi oleh kebutuhan mereka dan memilih jenis media untuk memuaskan kebutuhannya. Penggunaan media dapat diukur melalui hubungan individu dengan media, jenis media, dan jumlah waktu yang diukur menggunakan intensitas (Lometti, Reeves, \& Bybee, 1977).

Sebuah teori media yaitu uses and gratification menganggap media massa tidak memiliki kekuatan untuk memengaruhi audiens, melainkan khalayak menggunakan media massa tentunya berdasarkan atas keperluan dan kebutuhan yang berbeda-beda. Herber Blumler dan Elihu Katz mengemukakan bahwa pengguna media memiliki otoritas dalam memilih media (Hetharia, 2013). Uses and gratification lebih menspesifikasikan pada pendekatan manusiawi dalam melihat media massa. Dengan demikian, manusia itu miliki otonomi, wewenang untuk memperlakukan media (Sianipar, 2013).

Berdasarkan deskripsi singkat yang telah dipaparkan, penulis mencoba melakukan sebuah penelitian dengan menguji sebuah penggunaan media dan hubungan yang mendasarinya berdasarkan sudut pandang teori uses and gratification.

\section{TINJAUAN PUSTAKA}

Menurut W. Rubin \& Windahl (1986) penggunaan media adalah kegiatan memilih, mengkonsumsi, memproses dan menginterpretasi media sekaligus kontennya. Penggunaan media sering dikatakan kebiasaan menggunakan media (media habit) berulang kali atau dalam situasi yang sama setiap waktu (Naab \& Schnauber, 
2014). Rosengren, Wenner \& Palmgreen (1985) memberikan sebuah contoh bahwa ritual penggunaan televisi menunjukkan hubungan dalam aspek aktivitas audiens seperti selektivitas dan arah tujuan. Penggunaan media dapat diukur melalui hubungan individu dengan media, jenis media, dan jumlah waktu yang diukur menggunakan frekuensi, durasi dan intensitas (Lometti, Reeves, \& Bybee, 1977).

Media digunakan ke dalam seluruh siklus kehidupan memiliki implikasi untuk berbagai konsep termasuk audiens, efek media, alternatif fungsional, dan ketergantungan media (Rosengren, Wenner, \& Palmgreen, 1985). Kegiatan penggunaan media secara berulang tidak lepas dari kegiatan khalayak dalam mengelola intensitas yang dijelaskan oleh Lometti, Reeves, \& Bybee (1977). Penggunaan media berperan sebagai penghubung antara keduanya, di mana media dianggap berusaha memenuhi motif khalayak, jika motif yang diharapkan terpenuhi maka kebutuhan khalayak akan sebuah kepuasan juga terpenuhi dengan adanya penggunaan media sebagai perantara.

Uses and gratification merupakan sebuah model teori yang memandang khalayak sebagai audiens yang aktif menggunakan media. Teori uses and gratification merupakan kebalikan dari teori peluru atau teori jarum hipodermik, di mana dalam teori tersebut media dianggap sangat aktif dan sementara khalayak berada di pihak yang pasif (Nuruddin, 2007). Teori uses and gratification menjelaskan bagaimana sebuah media dapat memenuhi kebutuhan pribadi sosial khalayak yang aktif dalam menggunakan media (Santoso \& Setiansah, 2010). Elihu Katz mempopulerkan teori ini pada tahun 1959 dan dinyatakan secara formal oleh Katz, Jay G. Blumler, dan Michael Gurevith pada tahun 1970 (Littlejohn, Foss, \& Oetzel, 2017).

Model yang digunakan dalam penelitian ini adalah model uses and gratification klasik yang dipopulerkan oleh Elihu Katz di mana asumsi dasar uses and gratification sebagai: (1) asal sosial dan psikologis dari; (2) Kebutuhan yang menghasilkan; (3) Harapan-harapan; dari (4) Media massa atau sumber lain yang mengarah pada; (5) pola diferensial dari paparan media (atau keterlibatan dalam kegiatan lain); yang mengakibatkan (6) pemenuhan kebutuhan dan; (7) konsekuensi lainnya (Rosengren, Wenner, \& Palmgreen, 1985).

Motif khalayak dalam menggunakan media tentunya berbeda-beda tergantung kebutuhan. Menurut McQuail (1991) motif penggunaan media dibagi menjadi empat kelompok di antaranya informasi, identitas pribadi, hiburan dan integrasi interaksi sosial. Motif hiburan dijelaskan ketika seseorang menggunakan media maka akan mendapatkan kesenangan dan dapat mengisi waktu luang serta bersantai. Berbicara tentang motif tidak akan terlepas dari sebuah kepuasan. Philip Kotler menjelaskan konsep kepuasan sebagai ekspresi perasaan senang atau kecewa seseorang terhadap suatu harapan, misalnya ketika orang membaca koran pagi, mendengarkan laporan cuaca dan menonton televisi pada jam tertentu menjelaskan sebuah interaksi dengan media membutuhkan ritme dan waktu tersendiri (Hetharia, 2013). Sehingga dapat ditarik benang merah bahwa terpenuhinya kebutuhan seseorang dalam menggunakan media merupakan sebuah kepuasan yang diperoleh berdasarkan motif yang dicari.

\section{METODE}

Pendekatan kuantitatif digunakan dalam penelitian ini dengan tujuan untuk menjelaskan suatu fenomena sosial yang dapat diukur. Riset kuantitatif adalah suatu masalah yang hasilnya dapat digeneralisasikan (Kriyantono, 2010). Eksplanatif dimaksudkan untuk mengetahui pengaruh terjadinya sesuatu serta menjelaskan suatu generalisasi sampel terhadap populasi atau menjelaskan hubungan, perbedaan, atau pengaruh suatu variabel dan variabel lain (Nazhifah, 2017).

Kueisoner digunakan sebagai instrumen pengumpulan data dengan tujuan untuk memperoleh informasi tentang sejumlah responden yang dianggap mewakili populasi tertentu. Terdapat 525 populasi mahasiswa dalam penelitian ini, dengan probalitas sampling sebesar 84 berdasarkan perhitungan menggunakan slovin.

Definisi konseptual pada uji korelasi, motif diasumsikan sebagai variabel independen yang dikategorikan ke dalam indikator motif hiburan. Penggunaan diasumsikan sebagai variabel intervening, yang dikategorian ke dalam intensitas. Kepuasan merupakan variabel dependen yang dikategorikan ke dalam kepuasan hiburan. Keberadaan variabel intervening digunakan sebagai variabel pengontrol korelasi antara variabel independen dengan variabel dependen.

Pada definisi operasional, motif hiburan didefinisikan sebagai kegiatan mencari pemecahan masalah yang dialami melalui program acara talk show yang ditonton, dapat bersantai dan 
beristirahat dari aktifitas, dan mengisi waktu luang ketika menonton program acara talk show. Intensitas penggunaan media didefinisikan sebagai tingkatan fokus seseorang menonton program talk show pada media televisi. Sedangkan kepuasan hiburan adalah terpenuhinya suatu kebutuhan yang didapatkan apabila motif hiburan terpenuhi.

Berdasarkan penjelasan yang telah penulis paparkan maka dapat ditarik hopitesis $\mathrm{H}_{0}$ : Tidak ada pengaruh intensitas menonton program acara talk show terhadap korelasi antara motif hiburan dengan kepuasan hiburan. $\mathrm{H}_{\mathrm{a} \text { : }}$ Ada pengaruh intensitas menonton program acara talk show terhadap korelasi antara motif hiburan dengan kepuasan hiburan.

\section{HASIL DAN PEMBAHASAN}

Penelitian ini berupaya untuk menguji sebuah teori uses and gratification klasik yang dipopulerkan oleh Elihu Katz dengan hanya memfokuskan pada motif hiburan, kepuasan hiburan, dan intensitas menonton program acara talk show melalui media televisi. Hetharia (2013) dalam penelitiannya menjelaskan bahwa kepuasan khalayak dalam menggunakan media merupakan sebuah kepuasan yang diperoleh berdasarkan motif tertentu. Sehingga, ketika perasaan senang dalam menggunakan media diikuti dengan pengunaan media secara berulang, maka di situlah terjadi proses kepuasan menggunakan media.

Kepuasan dari pemenuhan kebutuhan yang didapat oleh khalayak merupakan efek dari penggunaan media dengan dapat mengevaluasi kemampuan media untuk memberikan sebuah kepuasan. Berdasarkan kuesioner yang telah didistribusikan kepada 84 responden, maka didapatkan hasil penghitungan distribusi frekuensi pada motif hiburan, intensitas, dan kepuasan hiburan menonton program acara talk show melalui media televisi didapatkan hasil sebagai berikut:

\section{Motif Hiburan}

Indikator motif hiburan dalam variabel ini diturunkan ke dalam tiga pertanyaan untuk melihat motif hiburan yang diinginkan oleh responden ketika menonton program acara talk show pada media televisi. Hasilnya dapat dilihat pada tabel di bawah ini:
Tabel 1.

Apakah dapat mencari hiburan saat menonton program acara talk show

\begin{tabular}{|c|c|c|}
\hline Kategori & Frekuensi & Prosentase \\
\hline Tidak Ingin & - & - \\
\hline Kurang Ingin & 4 & 4,8 \\
\hline Cukup Ingin & 36 & 42,9 \\
\hline Sangat Ingin & 44 & 52,4 \\
\hline Jumlah & $\mathbf{8 4}$ & $\mathbf{1 0 0 \%}$ \\
\hline
\end{tabular}

Sumber: Data primer diolah peneliti, 2019

Pada pertanyaan apakah responden ingin mencari hiburan saat menonton program acara talk show, lebih dari setengah dari populasi responden menjawab sangat ingin. Dengan demikian dapat kita amati program talk show yang ditonton oleh responden adalah program yang menghadirkan pembahasan yang menghibur dengan materi yang mudah dipahami.

Tabel 2.

Apakah dapat menghilangkan kebosanan saat menonton acara talk show

\begin{tabular}{|c|c|c|}
\hline Kategori & Frekuensi & Prosentase \\
\hline Tidak Ingin & 1 & 1,2 \\
\hline Kurang Ingin & 6 & 7,1 \\
\hline Cukup Ingin & 38 & 45,2 \\
\hline Sangat Ingin & 39 & 46,4 \\
\hline Jumlah & $\mathbf{8 4}$ & $\mathbf{1 0 0 \%}$ \\
\hline
\end{tabular}

Sumber: Data primer diolah peneliti, 2018

Data pada tabel di atas menunjukkan kesamaan pada tabel sebelumnya di mana pilihan cukup ingin dan sangat ingin mendominasi pilihan responden. Keinginan responden untuk menghilangkan kebosanan saat menonton program talk show terbilang prosentasenya tinggi.

Tabel 3.

Apakah dapat melepaskan diri dari permasalahan saat menonton acara talk show

\begin{tabular}{|c|c|c|}
\hline Kategori & Frekuensi & Prosentase \\
\hline Tidak Ingin & 3 & 3,6 \\
\hline Kurang Ingin & 21 & 25,0 \\
\hline Cukup Ingin & 35 & 41,7 \\
\hline Sangat Ingin & 25 & 29,8 \\
\hline Jumlah & $\mathbf{8 4}$ & $\mathbf{1 0 0 \%}$ \\
\hline
\end{tabular}

Sumber: Data primer diolah peneliti, 2019 
Berdasarkan tabel di atas mayoritas responden memilih cukup ingin dengan prosentase cukup ingin sebesar $41,7 \%$, sangat ingin 29,8\%, kurang ingin $25,0 \%$, dan tidak ingin 3,6\%. Masih terdapat 24 orang yang beranggapan bahwa ketika menonton tayangan talk show tidak akan menyelesaikan masalah yang sedang dihadapi.

\section{Intensitas}

Indikator intensitas dalam variabel ini diturunkan ke dalam tiga pertanyaan untuk melihat intensitas penggunaan oleh responden ketika menonton program acara talk show pada media televisi. Hasilnya dapat dilihat pada tabel di bawah ini:

Tabel 4.

Apakah fokus menonton acara talk show di televisi sampai selesai

\begin{tabular}{|c|c|c|}
\hline Kategori & Frekuensi & Prosentase \\
\hline Tidak pernah fokus & 3 & 3,6 \\
\hline Jarang fokus & 11 & 13,1 \\
\hline Terkadang fokus & 63 & 75,0 \\
\hline Selalu fokus & 7 & 8,3 \\
\hline Jumlah & $\mathbf{8 4}$ & $\mathbf{1 0 0 \%}$ \\
\hline
\end{tabular}

Sumber: Data primer diolah peneliti, 2019

Tanggapan mahasiswa ada pertanyaan apakah fokus menonton acara talk show di televisi sampai selesai didominasi oleh sikap "terkadang fokus". Hal ini menjelaskan bahwa tingkat fokus responden dalam menonton program talk show pada media televisi tidak selamanya fokus mengikuti jalannya acara, berarti keadaan responden selama menonton acara talk show melalui media televisi diikuti dengan melakukan aktivitas lain.

Tabel 5.

Apakah memindah channel lain ketika acara talk show sedang berlangsung

\begin{tabular}{|c|c|c|}
\hline Kategori & Frekuensi & Prosentase \\
\hline $\begin{array}{c}\text { Selalu memindah } \\
\text { channel }\end{array}$ & 4 & 4,8 \\
\hline $\begin{array}{c}\text { Terkadang } \\
\text { memindah channel }\end{array}$ & 48 & 57,1 \\
\hline $\begin{array}{c}\text { Jarang memindah } \\
\text { channel }\end{array}$ & 26 & 31,0 \\
\hline $\begin{array}{c}\text { Tidak pernah } \\
\text { memindah channel }\end{array}$ & 6 & 7,1 \\
\hline Jumlah & $\mathbf{8 4}$ & $\mathbf{1 0 0 \%}$ \\
\hline
\end{tabular}

Sumber: Data primer diolah peneliti, 2019
Tanggapan responden mayoritas cukup konsisten dalam menonton suatu tayangan talk show di televisi, terbukti dari 84 responden yang selalu memindah-mindah channel jumlah sangat sedikit dibandingkan dan yang kadang, jarang dan tidak pernah memindah channel. Hal ini berarti mahasiswa Komunikasi Universitas Sebelas Maret angkatan 2015 sampai 2017 mayoritas jarangjarang memindah channel selama menonton acara talk show yang ditayangkan di televisi.

\section{Tabel 6.}

Apakah menonton acara talk show di televisi sambil mengerjakan pekerjaan lain

\begin{tabular}{|c|c|c|}
\hline Kategori & Frekuensi & Prosentase \\
\hline $\begin{array}{c}\text { Selalu sambil } \\
\text { mengerjakan } \\
\text { pekerjaan lain }\end{array}$ & 6 & 7,1 \\
\hline $\begin{array}{c}\text { Terkadang sambil } \\
\text { mengerjakan } \\
\text { pekerjaan lain }\end{array}$ & 14 & 16,7 \\
\hline $\begin{array}{c}\text { Jarang sambil } \\
\text { mengerjakan } \\
\text { pekerjaan lain }\end{array}$ & 9 & 10,7 \\
\hline $\begin{array}{c}\text { Tidak pernah } \\
\text { sambil } \\
\text { mengerjakan } \\
\text { pekerjaan lain }\end{array}$ & $\mathbf{8 4}$ & $\mathbf{1 0 0 \%}$ \\
\hline Jumlah &
\end{tabular}

Sumber: Data primer diolah peneliti, 2019

Sebagian besar responden selama menonton acara talk show di televisi tidak sambil mengerjakan pekerjaan lain, responden cenderung fokus hanya menonton. Sikap responden didominasi oleh sikap "kadang dan jarang" untuk mengerjakan pekerjaan sambil menonton acara talk show di televisi.

\section{Kepuasan Hiburan}

Indikator kepuasan integrasi \& interaksi sosial dalam variabel ini terdiri dari tiga pernyataan yang berasal dari motif integrasi \& interaksi sosial yang 
diinginkan dengan pernyataan yang hampir sama. Hasilnya dapat dilihat pada tabel berikut ini:

Tabel 7.

\section{Apakah menonton acara talk show di televisi bisa mendapatkan hiburan}

\begin{tabular}{|c|c|c|}
\hline Kategori & Frekuensi & Prosentase \\
\hline $\begin{array}{c}\text { Tidak } \\
\text { Mendapatkan }\end{array}$ & 3 & 3,6 \\
\hline $\begin{array}{c}\text { Kurang } \\
\text { Mendapatkan }\end{array}$ & 3 & 3,6 \\
\hline $\begin{array}{c}\text { Cukup } \\
\text { Mendapatkan }\end{array}$ & 47 & 56,0 \\
\hline $\begin{array}{c}\text { Sangat } \\
\text { Mendapatkan }\end{array}$ & 31 & 36,9 \\
\hline Jumlah & $\mathbf{8 4}$ & $\mathbf{1 0 0 \%}$ \\
\hline
\end{tabular}

Sumber: Data primer diolah peneliti, 2019

Data di atas menjelaskan bahwa responden merasa puas dengan menonton acara talk show di televisi karena responden juga merasakan mendapatkan hiburan saat menonton acara talk show. Hal ini terbukti dari tanggapan responden yang menyatakan bahwa 56\% responden merasakan "cukup mendapatkan hiburan" dengan $36,9 \%$ merasakan sangat mendapatkan hiburan saat menonton acara talk show.

Tabel 8.

Apakah menonton acara talk show di televisi dapat menghilangkan kebosanan

\begin{tabular}{|c|c|c|}
\hline Kategori & Frekuensi & Prosentase \\
\hline Tidak Mendapatkan & 2 & 2,4 \\
\hline $\begin{array}{c}\text { Kurang } \\
\text { Mendapatkan }\end{array}$ & 6 & 7,1 \\
\hline $\begin{array}{c}\text { Cukup } \\
\text { Mendapatkan }\end{array}$ & 44 & 52,4 \\
\hline $\begin{array}{c}\text { Sangat } \\
\text { Mendapatkan }\end{array}$ & 32 & 38,1 \\
\hline Jumlah & $\mathbf{8 4}$ & $\mathbf{1 0 0 \%}$ \\
\hline
\end{tabular}

Sumber: Data primer diolah peneliti, 2019

Data di atas menunjukkan bahwa sebagian besar responden merasakan cukup dengan sangat mendapatkan kepuasan yang dapat menghilangkan kebosanan saat menontoton acara talk show di televisi. Hal ini terbukti dari sikap responden lebih banyak memilih cukup sebesar $52,4 \%$ dengan sikap sangat sebesar $38,1 \%$.
Tabel 9.

Apakah menonton talk show di televisi dapat melepaskan diri dari permasalahan

\begin{tabular}{|c|c|c|}
\hline Kategori & Frekuensi & Prosentase \\
\hline Tidak Mendapatkan & 9 & 10,7 \\
\hline $\begin{array}{c}\text { Kurang } \\
\text { Mendapatkan }\end{array}$ & 18 & 21,4 \\
\hline Cukup Mendapatkan & 40 & 47,6 \\
\hline $\begin{array}{c}\text { Sangat } \\
\text { Mendapatkan }\end{array}$ & 17 & 20,2 \\
\hline Jumlah & 84 & $100 \%$ \\
\hline
\end{tabular}

Sumber: Data primer diolah peneliti, 2019

Berdasarkan sikap dengan pertanyaan responden tentang "menonton acara talk show di televisi saudara dapat melepaskan diri dari permasalahan yang sedang dialami" dapat diketahui bahwa sebagaian besar responden meraskan puas saat menonton acara talk show di televisi karena dapat melepaskan diri dari permasalahan yang sedang dialami. Hal ini terbukti sikap responden yang merasakan cukup sebesar $47,6 \%$ dengan yang merasakan sangat sebesar 20,2\%. Sehingga dapat ditarik kesimpulan bahwa mayoritas responden merasakan bahwa menonton program acara talk show dapat melepaskan diri dari permasalahan yang sedang dialami.

\section{Hasil Uji Korelasi}

Berikut ini akan dibuktikan seberapa kuat hubungan pada motif dengan kepuasan menonton program talk show melalui media televisi.

Berdasarkan penghitungan di atas, adanya variabel pengontrol ternyata besaran koefisien korelasinya 0,448 dengan besaran signifikansinya tetap 0,000 lebih kecil dibandingkan dengan 0,05. Sehingga dapat disimpulkan tidak ada pengaruh variabel intensitas terhadap hubungan antara motif hiburan dengan kepuasan hiburan. Dengan kata lain ketika responden intens menonton program acara talk show tidak memengaruhi kepuasan hiburan yang didapatkan. Melainkan kepuasan hiburan yang diperoleh responden berasal dari besarnya motif hiburan yang diinginkan. Jadi korelasi pada motif hiburan dengan kepuasan hiburan adalah murni bukan karena pengaruh variabel intensitas. Jadi hipotesis nul yang mengatakan tidak ada pengaruh penggunaaan pada korelasi antara motif hiburan dengan kepuasan hiburan diterima. 
Tabel 10.

Korelasi Parsial: Motif hiburan sebagai variabel independent. Kepuasan hiburan sebagai variabel dependent dan intensitas sebagai variabel intervening

\begin{tabular}{|c|c|c|c|c|}
\hline \multicolumn{3}{|l|}{ Control Variables } & \multirow{2}{*}{$\begin{array}{l}\begin{array}{l}\text { Zscore (skor_motif_- } \\
\text { hiburan_TV) }\end{array} \\
1,000\end{array}$} & \multirow{2}{*}{\begin{tabular}{|l|}
$\begin{array}{l}\text { Zscore (skor_kepuasa } \\
\text { hiburan_TV) }\end{array}$ \\
, 448 \\
, 000 \\
81
\end{tabular}} \\
\hline Zscore(skor_ & $\begin{array}{l}\text { Zscore(skor_ } \\
\text { motif_- } \\
\text { hiburan_TV) }\end{array}$ & $\begin{array}{l}\text { Correlation } \\
\text { Significance } \\
\text { (1-tailed) } \\
\text { df }\end{array}$ & & \\
\hline penggunaan_TV) & $\begin{array}{l}\text { Zscore(skor_ } \\
\text { kepuasan_- } \\
\text { hiburan_TV) }\end{array}$ & $\begin{array}{l}\text { Correlation } \\
\text { Significance } \\
\text { (1-tailed) } \\
\text { df }\end{array}$ & $\begin{array}{l}, 448 \\
, 000 \\
81\end{array}$ & $\begin{array}{l}1,000 \\
0\end{array}$ \\
\hline
\end{tabular}

Sumber: Data primer diolah peneliti, 2019

Hasil uji korelasi menjelaskan bahwa intensitas menonton program tayangan talk show melalui media televisi tidak memengaruhi kepuasan hiburan yang didapatkan oleh responden, melainkan tingginya tingkat kepuasan hiburan yang didapatkan berasal dari besarnya motif hiburan yang diinginkan. Maka dalam penelitian ini menjelaskan hasil yang berbeda, di mana motif yang diartikan sebagai keinginan kuat khalayak dalam mengakses media mendorong seseorang menggunakan media sebagai sarana untuk memenuhi kebutuhannya sebagai efek terjadinya kepuasan. Akan tetapi besarnya kepuasan yang didapat berasal dari tingginya motif yang diinginkan terlepas dari bagaimana intensitas responden menonton program acara talk show yang ditayangkan melalui televisi.

\section{SIMPULAN}

Hasil penelitian yang telah dilakukan menjelaskan bahwa intensitas tidak memengaruhi hubungan antara motif hiburan dengan kepuasan hiburan. Tingginya keinginan responden untuk menonton suatu tayangan, mendorong psikologinya untuk menggunakan media. Terlepas dari tinggi atau rendahnya terpaan media yang dirasakan oleh responden, tidak menjadi pengaruh tingginya kepuasan yang didapatkan. Dikarenakan tingginya kepuasan berasal dari kuatnya keinginan responden untuk menggunakan media. Jadi dapat dikatakan hasil uji korelasi parsial pada penelitian ini dapat membuktikan keberadaan teori uses and gratification, di mana asal sosial dan psikologis seseorang akan kebutuhan media menghasilkan kuatnya motif yang mendorong khalayak menggunakan media sebagai sarana untuk dapat memenuhi kebutuhannya. Seperti yang dijelaskan oleh Kadir (2014) bahwa khalayak mempunyai alasan serta kebebasan atas dirinya sendiri untuk mengontrol penggunaan suatu media tertentu.

\section{DAFTAR PUSTAKA}

Abdullah, A., \& Puspitasari, L. (2018). Media Televisi di Era Internet. ProTVF, 2(1), 101.

Dewi, C. T. (2001). Kompetisi Antara Stasiun Televisi di Indonesia (Analisis dan Aplikasi Teori Niche dan User Gratification dalam Penelitian Tentang Kompetisi Antara RCTI, SCTV, dan Indosiar). Jakarta: Universitas Indonesia.

Haqqu, R. (2019). Pengaruh Penggunaan Media Terhadap Hubungan Antara Motif Dengan Kepuasan Menonton Program Acara Talk Show Melalui Televisi dan Youtube (Studi Korelasi dan Asosiasi di Kalangan Mahasiswa S1 Ilmu Komunikasi Universitas Sebelas Maret Angkatan 2015 Sampai 201. In Universitas Sebelas Maret (Vol. 1, Issue 1).

Hetharia, B. (2013). Motif dan Kepuasan Penggunaan Blackberry di Lingkungan Seskoau Lembang. Surakarta: Universitas Sebelas Maret.

Komara, I. (2017, Desember 21). news.detik.com. Retrieved from detikNews: https://news.detik. com/berita/d-3780733/survei-kualitas-siarantv-kpi-program-infotainment-paling-rendah

Kriyantono, R. (2010). Teknik Praktis Riset Komunikasi. Jakarta: Kencana Prenada Media Group. 
Littlejohn, S. W., \& Foss, K. A. (2010). Theories off Human Coummunication. USA: Waveland Press.

Littlejohn, S. W., Foss, K. A., \& Oetzel, J. G. (2017). Theories Of Human Communication (Eleventh ed.). USA: Waveland Press.

Lometti, G. E., Reeves, B., \& Bybee, C. R. (1977). Investigating the assumptions of uses and gratifications research. Communication Research 4(3), 321-338.

Lubis, M. (2017). Nielsen. Retrieved Januari 5, 2018, from www.nielsen.com: http://www.nielsen. com/id/en/press-room/2017/tren-baru-dikalangan-pengguna-internet-di-indonesia. print.html

McQuail, D. (1991). Teori Komunikasi Massa. Jakarta: Erlangga.

McQuail, D. (1996). Teori Komunikasi Massa. Jakarta: Erlangga.

Naab, T. K., \& Schnauber, A. (2014). Habitual initiation of media use and a responsefrequency measure for its examination. Media Psychology, 19(1), 126-155.

Nuruddin. ( 2007). Pengantar Komunikasi Massa. Jakarta: Rajawali Pers.

Permana, R. S. M., Abdullah, A., \& Mahameruaji, J. N. (2019). Budaya Menonton Televisi di Indonesia: Dari Terrestrial Hingga Digital. ProTVF, 3(1), 53.

Rosengren, K. E., Wenner, L. A., \& Palmgreen, P. (1985). Media Gratifications Research. USA: Sage Publications Inc.

Santoso, E., \& Setiansah, M. (2010). Teori Komunikasi. Yogyakarta: Graha IImu.

Sianipar, A. P. (2013). Pemanfaatan Youtube di Kalangan Mahasiswa (Studi Penggunaan Youtube di Kalangan Mahasiswa Ilmu Komunikasi FISIP USU dengan Pendekatan Uses and Gratification. Jurnal IImu Komunikasi FLOW, Vol 2 (3), 1-10.

Wibowo, F. (2007). Teknik Produksi Program Televisi. Yogyakarta: Pinus Book Publisher. 